\title{
Prevalence of overweight and obesity among rural early adolescents in central part of Vidarbha, Maharashtra- A Cross Sectional study
}

\author{
Prajapati $\mathbf{K}^{1}$, Nayak $\mathbf{S}^{2}$, Dhande $\mathbf{N}^{3}$, Mudey $\mathrm{A}^{4}$ \\ ${ }^{1}$ Dr. Kshatrapal Prajapati, Resident, Department of Community Medicine, JNMC, Sawangi (M), Wardha, \\ ${ }^{2}$ Dr. Smrutiranjan Nayak, Associate Professor, Department of Community Medicine, KIMS, Bhubaneswar, \\ Odisha, ${ }^{3}$ Dr. Nikhil Dhande, Assistant Professor, Department of Community Medicine, JNMC, Sawangi (M), \\ Wardha, ${ }^{4}$ Dr. Abhay Mudey, Professor, Department of Community Medicine, JNMC, Sawangi (M), Wardha, \\ Maharashtra, India.
}

Address for Correspondence: Dr. Smrutiranjan Nayak, Email: dr.smrutiranjannayak@gmail.com

\begin{abstract}
Background: According to W.H.O number of over-weight children under the age group of five was estimated to be over 42 million and nearly close to 35 million of these were living in developing countries. Obesity in children and adolescents is defined as a BMI greater than the 95th percentile. Objective: To find out the prevalence of overweight and obesity in school going early adolescents. 2) To find out the factors contributing to early adolescent overweight/obesity. Method: School-going children between 11-15yrs. A cross-sectional (observational) study was carried out in middle- schools (5th to 7th standard) and high-schools (8th to 10th standard) of Alphonsa High School of Sawangi. Result: Prevalence of over-weight in early adolescent was found to be $15.83 \%$ and obese was $11.18 \%$. Obese school going students who watched television for 1 hour were $02.48 \%$, those watching TV for 2 hours were $03.72 \%$ and more than 2 hours were $04.96 \%$. Obesity was found to be more in children watching television for longer duration. Conclusion: Overweight/obesity among children are progressing towards epidemic level. Eating habit of junk food is on rise.
\end{abstract}

Key words: Obesity, School Health, Junk Foods

\section{Introduction}

According to W.H.O the prevalence in 2010 the number of overweight children under the age of five, is estimated to be over 42 million. Close to 35 million of these are living in developing countries. As of 2005 the WHO estimates that at least 400 million adults $(9.8 \%)$ are obese. $7-10 \%$ in Indian children.

Obesity in children and adolescents is defined as a BMI greater than the 95th percentile [1]. It was observed that $30 \%$ of obesity begins in childhood and out of that 50 to $80 \%$ became obese adults [2]. A study conducted by Patnaik L in 2015, observed that the prevalence of overweight, obesity was $27.8 \%$ (private schools $45.2 \%$, government

Manuscript received: $4^{\text {th }}$ July 2017

Reviewed: $14^{\text {th }}$ July 2017

Author Corrected: $23^{\text {rd }}$ July 2017

Accepted for Publication: $31^{\text {st }}$ July 2017
Schools 10.5\%). BMI, Waist Circumference and Waist-hip ratio were significantly higher among private school students [3].

Consumption of fast foods has become almost a global phenomenon. India's fast-food industry is expanding at the rate of $40 \%$ every year. India ranks 10th in the fast food per capita spending figures with $2.1 \%$ of expenditure in annual total spending [4].

Popularity of these food stuffs in this age of urbanization has been attributed to quick preparation and convenience of finishing a meal within no time. Great taste, attractive appearance along with advertising has played a major role in attracting people particularly adolescents to the selling joints [5]. 
This increase in childhood obesity has led to increase in life-threatening conditions particularly non communicable diseases in developing countries [6]. Dental cavity was found as another common ailment in school children which results due to dense sugar content in fast foods [7]. Food additives used in these food stuffs were found to be carcinogenic and can be allergic causing asthma and rashes which were also seen frequently among children.

Therefore this study was done to find out the prevalence of overweight, obesity in school going early adolescents and the factors which contributes to the childhood overweight and obesity

Aim: Prevalence of Overweight and Obesity among Rural Early Adolescents in central Part of Vidarbha, Maharashtra- A Cross Sectional Study

\section{Objectives}

1. To find out the prevalence of overweight and obesity in school going early adolescents.

2. To find out the factors contributing to early adolescent overweight/obesity.

\section{Materials \& Methods}

Reference Population: School going early adolescents of 11-15years

Study Population: Students of class $5^{\text {th }}$ to $10^{\text {th }}$ Std. of Alphonsa High School (322).

Study Design and Settings: A cross-sectional (observational) study was carried out in middle- schools (5th to 7th standard) and high-schools (8th to 10th standard) of Alphonsa High School of Sawangi.

Study Duration: The study was conducted from August to November 2015.

Sample Size: Sample size was calculated as 322 with 30\% prevalence [2] of obesity in childhood and $5 \%$ of allowable error and power of $95 \%$.

\section{Sampling Method}

- Systematic Random Sampling was done.

- 25 students were selected from each division.

\section{Total sections}

1) $5^{\text {th }} \mathrm{std}-3 \mathrm{sec}$

2) $6^{\text {th }} \mathrm{std}-2 \mathrm{sec}$

3) $7^{\text {th }}$ std $-2 \mathrm{sec}$

4) $8^{\text {th }} \mathrm{std}-3 \mathrm{sec}$

5) $9^{\text {th }}$ std-3 sec

Approximately 25 students from each section were selected by systematic random sampling method from attendance register. In case of absentees next roll number was included till the required 25 students from each division was fulfilled and this procedure was repeated in the subsequent class till the required sample size of 322 was attained. A pre-designed structured questionnaire was used to interview the study participants to elicit the information on individual characteristics like Age, Sex, Eating habits, and time spent on television viewing and outdoor games. Anthropometric measurements viz. height, weight, waist circumference, hip circumference were measured.

Height was measured by stadiometer to the nearest centimetre without shoes. Weight was measured with light clothing and without shoes to the nearest 100 grams. WC $(\mathrm{cm})$ was measured using plastic tape measure at midpoint between the costal margin and iliac crest in the mid-axillary line in standing position and at the end of gentle expiration. Hip circumference was measured in centimetres at the prominence of buttocks. Body mass index (BMI) was calculated by weight in $\mathrm{kg}$ divided by height squared in meter square. 
All anthropometric measurements and data collection by questionnaire were done by a trained Medical Social Worker (M.S.W). Children were categorized according to their BMI using BMI percentile curves for Indian boys and girls from 5- 17 years. They were classified as: underweight (BMI $<3^{\text {rd }}$ percentile), normal (BMI 3rd percentile to adult equivalent of BMI $<23$ ), overweight (Adult equivalent of BMI 23 to adult equivalent of BMI 27.99) or obese (adult equivalent of $\mathrm{BMI} \geq 28$ ).

Consent: Consent of school authorities was obtained after explaining the objectives as well as the method of study. Verbal consent was taken from the teachers and students.

Statistical Analysis: Data was analyzed using SPSS 16.0 and Microsoft Excel. After detailed analysis, data was presented in different tabular forms.

World Health Organization Chart for gender-wise distribution of BMI (8).

\begin{tabular}{|c|c|c|c|c|c|c|}
\hline \multirow{2}{*}{$\begin{array}{c}\text { Age in } \\
\text { years }\end{array}$} & \multicolumn{4}{|c|}{ Boys } & \multicolumn{2}{c|}{ Girls } \\
\cline { 2 - 7 } & $\begin{array}{c}\mathbf{5} \text { percentile } \\
\text { percentile }\end{array}$ & $\begin{array}{c}\mathbf{8 5}^{\text {th }} \\
\text { percentile }\end{array}$ & $\begin{array}{c}\mathbf{9 5}^{\text {th }} \\
\text { percentile }\end{array}$ & $\begin{array}{c}\mathbf{8 5}^{\text {th }} \\
\text { percentile }\end{array}$ & $\mathbf{9 5}^{\text {th }}$ percentile $^{\text {percenyyyy}}$ \\
\hline 11 & 14.5 & 19.3 & 21.1 & 14.4 & 20.0 & 22.2 \\
\hline 12 & 14.9 & 20.1 & 22.1 & 14.9 & 20.9 & 23.3 \\
\hline 13 & 15.4 & 20.9 & 23.1 & 15.5 & 21.9 & 24.4 \\
\hline 14 & 16.0 & 21.9 & 24.2 & 16.0 & 22.9 & 25.5 \\
\hline 15 & 16.5 & 22.8 & 25.2 & 16.5 & 23.7 & 26.3 \\
\hline
\end{tabular}

\section{Result}

Table I reveals that total standard $5^{\text {th }}$ students were $23.52 \%, 6^{\text {th }}$ standard were $15.52 \%, 7^{\text {th }}$ standard were $15.52 \%, 8^{\text {th }}$ standard were $23.29 \%, 9^{\text {th }}$ standard were $22.36 \%$.

Table II shows that students who were underweight were $3.72 \%$, normal were $69.25 \%$, over-weight were $15.83 \%$, obese were $11.18 \%$.

Table III showed that students who consumed Potato chips \& snacks and were Overweight were $16.45 \%$ and Obese of $03.72 \%$, Similarly Overweight of $25.77 \%$ and Obese of $23.29 \%$ was found in Chocolate \& candy eaters. In Ice creams \& cold drink eaters Overweight were $06.21 \%$ and Obese $11.18 \%$. In students who consumed other fried food items, prevalence of overweight were $07.76 \%$ and Obese were $06.52 \%$.

Table IV revealed that, as the number of hours of watching television increased percentage of overweight and obese also increased. Overweight at watching television for 1 hour was $03.10 \%$, at 2 hours were $04.65 \%$ and more than 2 hours were $08.07 \%$. Obese school going students at 1 hour television watching were $02.48 \%$ at 2 hours were $03.72 \%$ and at more than 2 hours were $04.96 \%$.

Table-I: Standard and Sex-wise distribution of study population.

\begin{tabular}{|c|c|c|c|}
\hline \multirow{2}{*}{ Standard } & \multicolumn{2}{|c|}{ Sex (\%) } & \multirow{2}{*}{ Total (\%) } \\
\cline { 2 - 3 } & Female (\%) & Male (\%) & $75(23.29 \%)$ \\
\hline $\mathbf{5}^{\text {th }}$ & $30(34.88 \%)$ & $45(19.06 \%)$ & $50(15.52 \%)$ \\
\hline $\mathbf{6}^{\text {th }}$ & $16(18.60 \%)$ & $34(14.40 \%)$ & $50(15.52 \%)$ \\
\hline $7^{\text {th }}$ & $12(13.95 \%)$ & $38(16.10 \%)$ & $75(23.29 \%)$ \\
\hline $\mathbf{8}^{\text {th }}$ & $11(12.79 \%)$ & $64(27.11 \%)$ & $72(22.36 \%)$ \\
\hline $\mathbf{9}^{\text {th }}$ & $17(19.76 \%)$ & $55(23.30 \%)$ & 322 \\
\hline Total $^{2}$ & $86(26.70 \%)$ & $236(73.29 \%)$ & \\
\hline
\end{tabular}


Table-II: Gender-wise distribution of BMI.

\begin{tabular}{|c|c|c|c|c|c|}
\hline \multirow{2}{*}{ Classification } & \multicolumn{2}{|c|}{ Male } & \multicolumn{2}{|c|}{ Female } & \multirow{2}{*}{$\begin{array}{c}\text { Total } \\
\%\end{array}$} \\
\hline & No & $\%$ & No & $\%$ & \\
\hline Underweight $\left(<5^{\text {th }}\right.$ percentile $)$ & 1 & 00.42 & 11 & 12.79 & 03.72 \\
\hline Normal (5th percentile to less than the $85^{\text {th }}$ percentile) & 168 & 71.18 & 55 & 63.95 & 69.25 \\
\hline Overweight (85th to less than the $95^{\text {th }}$ percentile) & 42 & 17.79 & 9 & 10.46 & 15.83 \\
\hline Obese (Equal to or greater than the $95^{\text {th }}$ percentile) & 25 & 10.59 & 11 & 12.79 & 11.18 \\
\hline Total & 236 & 100 & 86 & 100 & 100 \\
\hline
\end{tabular}

Table- III: Habit of Eating Junk Food Vs BMI (Multiple responses).

\begin{tabular}{|c|c|c|c|c|}
\hline Food Item & Underweight & Normal & Overweight & Obese \\
\hline potato chips \& snacks & $10(03.10 \%)$ & $92(28.57 \%)$ & $53(16.45 \%)$ & $12(03.72 \%)$ \\
\hline chocolates \& candies & $9(02.79 \%)$ & $122(37.88 \%)$ & $83(25.77 \%)$ & $75(23.29 \%)$ \\
\hline ice creams \& cold drinks & $8(02.48 \%)$ & $64(19.87 \%)$ & $20(06.21 \%)$ & $36(11.18 \%)$ \\
\hline other fried foods & $7(02.17 \%)$ & $59(18.32 \%)$ & $25(07.76 \%)$ & $21(06.52 \%)$ \\
\hline
\end{tabular}

Table-IV: BMI Vs Watching Television.

\begin{tabular}{|c|c|c|c|c|c|c|}
\hline \multirow{2}{*}{ BMI } & \multicolumn{6}{|c|}{ Hours of watching television } \\
\cline { 2 - 7 } & \multicolumn{2}{|c|}{$<\mathbf{l}$ hour } & \multicolumn{2}{c|}{$\mathbf{1 - 2}$ hours } & \multicolumn{2}{c|}{$>\mathbf{2}$ hours } \\
\cline { 2 - 7 } & No. & \%o. & No & No. & \% \\
\hline Underweight & 06 & 01.86 & 04 & 01.24 & 2 & 00.62 \\
\hline Normal & 91 & 28.26 & 76 & 23.60 & 56 & 17.39 \\
\hline Overweight & 10 & 03.10 & 15 & 04.65 & 26 & 08.07 \\
\hline Obese & 08 & 02.48 & 12 & 03.72 & 16 & 04.96 \\
\hline
\end{tabular}

\section{Discussion}

In the present study prevalence of students who were underweight were $03.72 \%$, over-weight were $15.83 \%$ and obese were $11.18 \%$. A study in Mangalore by Joseph $\mathrm{N}$ et al [9] observed that out of 300 participants, $41(13.7 \%)$ were overweight and $8(2.7 \%)$ were obese. Goyal JP et. al. [12] observed obesity and overweight $6.55 \%$ and $13.9 \%$ respectively.

Patnaik L [3] observed that prevalence of overweight / obesity was $27.8 \%$ (private schools $45.2 \%$, government schools $-10.5 \%$ ).

In our study it was found that Potato chips \& snacks eaters had higher incidence of Overweight of (16.45\%) and Obese (03.72). Jaisheeba AA [6] observed frequency of daily consumption of junk food among the obese students to be about $33.6 \%$.

Overweight and its relation with watching television for 1 hour was $03.10 \%$, at 2 hours were $04.65 \%$ and more than 2 hours were $08.07 \%$. Obese school going students watching television for 1 hour was $02.48 \%$, for 2 hours was $03.72 \%$ and at more than 2 hours was $04.96 \%$. Goyal JP et. al [12] in Gujarat observed significant association between TV viewing and overweight. Jaisheeba AA [6] observed that most of the obese students spend their leisure time by watching television.

Rajat Vohra et al [10] observed that out of total of 407 children of 5 th to 12 th standard who participated in the study, only 141 (34.64\%) were normal, 246 (60.44\%) were undernourished, 17 $(4.17 \%)$ were overweight, and $3(0.73 \%)$ were obese.

Khadilkar VV [11] observed that overall prevalence of overweight and obesity was $18.2 \%$ by the IOTF classification and $23.9 \%$ by the WHO standards. The prevalence of overweight and obesity was higher in boys than girls.

Jagadeshan S [13] observed that prevalence of overweight/obesity was significantly higher in private compared to government schools both by the IOTF criteria [private schools: 21.4\%, government schools: $3.6 \%$ ]. 
Ashlesha Datar[14] observed that young children's access to junk foods in school is an important concern due to the strong correlation between childhood overweight and obesity in adolescence and adulthood. Those 5th graders who attend a combined school are much more likely to have junk food availability relative to those in elementary school.

Obesity is one of the numerous diseases of civilization in the contemporary world. It is a risk factor and a direct cause of many severe diseases, not only somatic, but also mental. Obesity can also be a reason for social exclusion. In consequence, obesity can even lead to death. In psychoanalysis the reasons for obesity are sought for in the specific relations in the family of an obese child.

Obesity is not a manifestation of constitutionallydetermined developmental disorders of the child but a result of the relation between the father and mother and the parents and child. According to this approach, the obesity of the child is a consequence of failure of the emotional relations in the family.

In the psychosomatic model obesity can be deemed a somatic reflection of failure in the functioning of the mental mechanisms of an individual. Obesity is an effect of inadequate interpretation of the child's cry by its parents. Parents think that a child crying out of emotion actually cries because he or she is hungry. As a consequence the child in emotional discomfort looks for food to satisfy its needs [15].

\section{Conclusion}

Prevalence of overweight and obesity was found to be $15.83 \% 11.18 \%$ respectively. Majority of them consumed Junk Foods. Most of the over-weight and obese adolescents were addicted to watching TV and being a Couch Potato. Thus factors such as consuming the Junk Foods and watching television are related to early adolescent over-weight and obesity.

Recommendation: Children form an important of a healthy society. Government, health planners, administrators and individuals, parent are equal partners in delivering this message. Based on our study and experience we recommend few points for better health of the children as well as their parents i.e. healthy food habits, nutritive values, lifestyle and behavioural modifications.

\section{Funding: Nil, Conflict of interest: None}

Permission of IRB: Yes

\section{References}

1. Childrens BMI http://www.cdc.gov/nccdphp / dnpa /healthyweight/assessing/bmi/childrens BMI/ about childrens BMI. htm [Accessed on 14 December 2015]

2. Obesity: preventing and managing global epidemic report of a WHO consultation. (WHO Technical report series No. 894) Geneva World Health Organization 2000.

3. Patnaik L, Pattanaik S, Sahu T, Rao EV. Overweight and Obesity among Adolescents, A Comparative Study Between Government and Private Schools. Indian Pediatric. 2015 Sep 8; 52 (9): 779-81

4. Allamani A. Addiction, risk, and resources. Subst Use Misuse. 2007;42(2-3):421-39.

5. Dixon HG, Scully ML, Wakefield MA, White VM, Crawford DA. The effects of television advertisements for junk food versus nutritious food on children's food attitudes and preferences. Soc Sci Med. 2007Oct;65(7):1311-23.Epub2007Jun 22.

6. AA Jaisheeba, R Sornaraj, K Gayathri. Influence of westernized culture and changed dietary habits on the BMI status of the school children of Tirunelveli. International Journal of Pharm Tech Research.2012 July-Sept; 4(3):1065-77

7. N Nisar, MH Qadri, K Fatima, SJ Perveen. Dietary habits and life style among the students of a Private Medical University, Karachi. Pak Med Assoc. 2009 Feb; 59(2):98-101

8. BMI-for-age Boys and Girls. World Health Organization, http://www.who.int/growthref /who 2007 _bmi_for_age/en/ (Accessed on 26 December 2015).

9. Joseph N, Nelliyanil M, Rai S, Y P RB, Kotian SM, Ghosh T, Singh M. Fast Food Consumption Pattern and Its Association with Overweight Among High School Boys in Mangalore City of Southern India. J Clin Diagn Res. 2015 May;9(5): LC13-7.doi: 10.7860/JCDR/ 2015/13103. 5969. Epub 2015May 1. 
10. Vohra R, Bhardwaj P, Srivastava JP, Srivastava S, Vohra A. Overweight and obesity among schoolgoing children of Lucknow city. J Family Community Med. 2011 May;18(2):59-62. doi: 10. 4103 / 2230-8229.83369.

11. Khadilkar VV, Khadilkar AV, Cole TJ, Chiplonkar SA, Pandit D. Overweight and obesity prevalence and body mass index trends in Indian children. Int J Pediatr Obes. 2011 Jun; 6(2-2):e21624. doi: 10.3109/17477166. 2010.541463. Epub 2010 Dec 16.

12. Goyal JP, Kumar N, Parmar I, Shah VB, Patel B. Determinants of Overweight and Obesity in Affluent Adolescent in Surat City, South Gujarat region, India. Indian J Community Med. 2011 Oct;36(4):296-300. doi: 10.4103/0970-0218.91418.

13. Jagadesan $\mathrm{S}$, Harish $\mathrm{R}$, Miranda $\mathrm{P}$, Unnikrishnan R, Anjana RM, Mohan V. Prevalence of overweight and obesity among school children and adolescents in Chennai. Indian Pediatr. 2014 Jul;51(7):544-9.

14. Datar A, Nicosia N. Junk Food in Schools and Childhood Obesity. J Policy Anal Manage. 2012 Spring;31(2):312-337.

15. Jeżewska-Zychowicz M., Pilska M. Psychology of Nutrition. Elected Questions. Publishing House SGGW; Warsaw, Poland: 2008.

\section{How to cite this article?}

Prajapati K, Nayak S, Dhande N, Mudey A. Prevalence of overweight and obesity among rural early adolescents in central part of Vidarbha, Maharashtra- A Cross Sectional study. Int J Med Res Rev 2017;5(07):725730.doi:10.17511/ijmrr. 2017.i07.11. 